\title{
SOLVOLYSIS OF THE TUMOR-INHIBITING Ru(III)-COMPLEX trans-TETRACHLOROBIS(INDAZOLE)RUTHENATE(III)
}

\author{
Thomas Pieper, Wolfgang Peti and Bernhard K. Keppler* \\ Institute of Inorganic Chemistry, University of Vienna, Waehringerstr. 42, A-1090 Vienna, \\ Austria
}

\begin{abstract}
The ruthenium(III) complex HInd trans-[ $\left.\left[\mathrm{RuCl}_{4} \text { (ind }\right)_{2}\right]$, with two trans-standing indazole (ind) ligands bound to ruthenium via nitrogen, shows remarkable activity in different tumor models in vitro and in vivo. The solvolysis of the complex trans-[RuCl$\left.{ }_{4}(\text { ind })_{2}\right]$ has been investigated by means of spectroscopic techniques (UV/vis, NMR) in different solvents. We investigated the indazolium as well as the sodium salt, the latter showing improved solubility in water. In aqueous acetonitrile and ethanol the solvolysis results in one main solvento complex. The hydrolysis of the complex is more complicated and depends on the $\mathrm{pH}$ of the solution as well as on the buffer system.
\end{abstract}

\section{Introduction}

Today, cisplatin is a well established chemotherapeutic drug, especially against testicular carcinomas, but expansion to a different or broader antitumor spectrum has not been obtained with cisplatin or direct analogues, like carboplatin. Some new developments like orally administrable platinum complexes or combination therapy are promising, but attention is more and more directed to non-platinum antitumor metal compounds. Among others, ruthenium complexes of the oxidation state $+1 \mid$ and $+1 \mid 1$ are under current investigation as alternative drugs to platinum-based tumor inhibitors [1,2,3,4]. Because of their different chemical characteristics and kinetics, the mode of action and spectrum of activity of these ruthenium compounds should differ significantly from the known platinum complexes. They possess a different redox behavior and undergo different hydrolysis reactions. As a result, a different interaction with biological targets can be expected and detected.

Especially ruthenium(III) complexes of the general formula $\mathrm{HL}\left[\mathrm{RuCl}_{4} \mathrm{~L}_{2}\right]$, with two transstanding heterocyclic ligands $L$ bound to ruthenium via nitrogen, show remarkable activity in different tumor models in vitro and in vivo. They exhibit excellent activity in an autochthonous colorectal tumor model, which is comparable to human colon tumors in its histological appearance and behavior against chemotherapeutics, with a tumor reduction of about $70 \%$ to $90 \%[5,6]$. Cisplatin is completely inactive in this model. Furthermore, these Ru(III)-complexes show antiproliferative activity in two human colon cancer cell lines (SW707 and SW948) [7]. The most promising complex contains two trans-standing indazole $(L=$ ind) ligands. It exhibits antineoplastic effects on proliferation of clonogenic cells from freshly explanted human tumors in a capillary soft agar cloning system [8]. Compared to the also very active imidazole $(L=i m)$ complex it is less toxic. The slightly different activity and significantly different toxicological profile of the imidazole and indazole complexes might be due to their different hydrolysis reactions and kinetics and binding preferences for biological targets. Aquation is an important step in the activation of cisplatin [9] and aqua complexes, in general, are orders of magnitude more labile than the corresponding chloro complexes $[10,11,12]$. It is also known that only aged aqueous solutions of HIm trans$\left[\mathrm{RuCl}_{4}(\mathrm{im})_{2}\right]$ react with DNA [13]. Therefore, the knowledge of hydrolysis or, in general, solvolysis products is of great importance for a deeper understanding of the mode of action of the ruthenium complexes.

The hydrolysis reactions of the imidazole complex $\mathrm{HIm}$ trans-[RuCl $\left.\mathrm{Cim}_{2}\right]$ have already been investigated by means of ${ }^{1} \mathrm{H}-\mathrm{NMR}$, EPR or UV/vis spectroscopy $[14,15,16]$. In each case hydrolysis to a monoaqua complex has been proposed in unbuffered aqueous solution, followed by the formation of both of the possible diaqua complex isomers with trans-standing imidazoles. The situation in phosphate-buffered solution was found to be more complicated.

Here we report on the solvolysis in ethanol, acetonitrile and dimethylsulfoxide and the hydrolysis of the indazole complex trans-[RuCl$\left.l_{4}(\text { ind })_{2}\right]^{-}$(see figure 1a). We investigated the indazolium as well as the sodium salt, the latter showing improved solubility in water. 


\section{Materials and Methods}

Solvents used were of analytical grade and dried with standard methods.

Elemental analysis C, H,N analysis were carried out on a Perkin Elmer $2400 \mathrm{CHN}$ Elemental Analyzer. $\mathrm{Cl}$ was analyzed by argentometry.

Spectrophotometric experiments were performed in a thermostated cell compartment in a Perkin Elmer Lambda 20 UV/vis spectrometer.

${ }^{1} \mathrm{H}$ NMR experiments were performed at $400.13 \mathrm{MHz}\left({ }^{1} \mathrm{H}\right)$ on a Bruker DPX 400 spectrometer. HInd trans-[RuCl${ }_{4}$ (ind $\left.)_{2}\right]$ [17] and $\mathrm{Na}$ trans-[RuCl 4 (ind $\left.)_{2}\right] \cdot 3 \mathrm{H}_{2} \mathrm{O}$ [18] were prepared as described elsewhere. To obtain "water-free" Na trans-[RuCl$\left.{ }_{4}(\text { ind })_{2}\right]$ for reactions in absolute solvents, the trihydrate is dissolved in acetonitrile and the complex salt precipitated by addition of diethylether and dried under vacuum. $\mathrm{C}_{14} \mathrm{H}_{12} \mathrm{Cl}_{4} \mathrm{~N}_{4} \mathrm{NaRu}(502.15)$ : calcd. $\mathrm{C} 33.49, \mathrm{H} 2.41, \mathrm{~N}$ 11.16; found: $\mathrm{C} 33.33, \mathrm{H} 2.66, \mathrm{~N} 11.05$. $\mathrm{H}-\mathrm{NMR}\left(400 \mathrm{MHz}, \mathrm{D}_{3}\right]$ acetonitrile): $\delta 4.31(2 \mathrm{H})$, $3.18(2 \mathrm{H}), 2.63(2 \mathrm{H}), 2.44(2 \mathrm{H}),-7.1(2 \mathrm{H}),-12.9(2 \mathrm{H}) \mathrm{ppm} .{ }^{13} \mathrm{C}-\mathrm{NMR}(100 \mathrm{MHz}$, acetonitriled3): $\delta 118.05,114.71,98.27,97.75 \mathrm{ppm}$.

Precipitate obtained from a solution of $\mathrm{Na}$ trans- $\left[\mathrm{RuCl}_{4}(\mathrm{ind})_{2}\right] \cdot 3 \mathrm{H}_{2} \mathrm{O}$ in water: The dark solid that precipitated in a nearly saturated solution of $\mathrm{Na}$ trans-[RuCl 4 (ind $\left.)_{2}\right] \cdot 3 \mathrm{H}_{2} \mathrm{O}$ in water at room temperature was filtered after one week. Elemental analysis, found: C 36.47, H 2.96, N 11.85, $\mathrm{Cl} 21.95$, calculated for [ $\left.\left[\mathrm{RuCl}_{3}\left(\mathrm{H}_{2} \mathrm{O}\right) \text { (ind) }\right)_{2}\right], \mathrm{C}_{14} \mathrm{H}_{14} \mathrm{Cl}_{3} \mathrm{~N}_{4} \mathrm{ORu}$ (461.72): C: $36.42, \mathrm{H} 3.06, \mathrm{~N}$ 12.13, $\mathrm{Cl} 23.04$. ${ }^{1} \mathrm{H}-\mathrm{NMR}(400 \mathrm{MHz}$, dmso-d6): $\delta 4.49,4.19,3.71,3.64,-4,-10 \mathrm{ppm}$ and, with $2 \%$ relative peak area, $7.17,7.40,7.80,8.75 \mathrm{ppm}$.

Precipitate obtained from a solution of $\mathrm{Na}$ trans- $\left[\mathrm{RuCl}_{4}(\text { ind })_{2}\right] \cdot 3 \mathrm{H}_{2} \mathrm{O}$ in acetonitrile / water: The dark solid that precipitated in a nearly saturated solution of $\mathrm{Na}$ trans-[RuCl${ }_{4}$ (ind $\left.)_{2}\right] \cdot 3 \mathrm{H}_{2} \mathrm{O}$ in acetonitrile / water (70/30) at room temperature was filtered after one week. Elemental analysis, found: $\mathrm{C}: 39.71, \mathrm{H} 2.95, \mathrm{~N} 14.37, \mathrm{Cl} 21.86$, calculated for $\left.\left[\mathrm{RuCl}_{3}\left(\mathrm{CH}_{3} \mathrm{CN}\right) \text { (ind) }\right)_{2}\right]$, $\mathrm{C}_{16} \mathrm{H}_{15} \mathrm{Cl}_{3} \mathrm{~N}_{5} \mathrm{Ru}$ (484.76): C 39.64, $\mathrm{H}$ 3.12, $\mathrm{N}$ 14.45, Cl 21.94. ${ }^{1} \mathrm{H}-\mathrm{NMR}\left(400 \mathrm{MHz}, \mathrm{CDCl}_{3}\right): \delta$ 9.09, $5.59,5.10,4.40,4.04,2.89,1.09,-2.22,-12$ and $-17 \mathrm{ppm}$.

\section{Results and Discussion}

\subsection{Solvolysis of $\mathrm{Na}$ trans-[RuCl$\left.l_{4}(\text { ind })_{2}\right]$}

$\mathrm{Na}$ trans-[RuCl (ind $\left._{2}\right]$ does not react in acetonitrile within two days. No changes in ${ }^{1} \mathrm{H}$ NMRand UV/vis-spectra can be seen. In the ${ }^{1} \mathrm{H}$ NMR spectrum of $\mathrm{Na}$ trans-[RuCl$\left.{ }_{4}(\text { ind })_{2}\right]$ the typical line broadening and chemical shifts due to the paramagnetic $\mathrm{Ru}(\mathrm{III})$-center can be observed $[19,20]$. The most upfield shifted signal at a chemical shift of $-13.0 \mathrm{ppm}$ represents the two protons at position 3 of the two equivalent indazole ligands. The signal at $-7.1 \mathrm{ppm}$ can be assigned to each proton at $\mathrm{N}-2$ because it disappears, due to rapid exchange, on addition of $\mathrm{D}_{2} \mathrm{O}$. The less broad and upfield shifted peaks at $2.45(2 \mathrm{~h}$ at C-4 or C-7), $2.63(2 \mathrm{H}$ at C-7 or C4), $3.18(2 \mathrm{H}$ at $\mathrm{C}-5$ or $\mathrm{C}-6)$ and $4.32 \mathrm{ppm}(2 \mathrm{H}$ at $\mathrm{C}-6$ or $\mathrm{C}-5)$, that can be assigned in pairs because of corresponding cross-peaks in the $\mathrm{H}, \mathrm{H}-\mathrm{COSY}$ experiment, represent the protons of the indazole ligands with a greater distance to the paramagnetic $\mathrm{Ru}(\mathrm{III})$-center [18].

The possibility that the spectra in a fresh solution of $\mathrm{Na}$ trans-[RuCl$\left.{ }_{4}(\text { ind })_{2}\right]$ do not represent the structure determined for the solid complex salt [18], could be ruled out by evaporating the solvent or precipitating the complex salt with diethylether and characterizing the obtained product again. No changes in the IR- or ${ }^{1} H$ NMR-spectra could be observed.

If a mixture of acetonitrile / water is used instead of pure acetonitrile, a transformation can be seen in ${ }^{1} \mathrm{H}$ NMR- and UV/vis-spectra. Na trans-[RuCl ${ }_{4}$ ind $\left._{2}\right]$ reacts in acetonitrile / water (70/30), the eluent mixture that is used as solvent in HPLC experiments of the compound, to a main solvolysis product. Figure $1 \mathrm{~b}$ shows the changes in ${ }^{1} \mathrm{H}$ NMR-spectra taken during 72 hours at room temperature. Four new peaks at a chemical shift of $3.77,3.56,0.44$ and $0.11 \mathrm{ppm}$ show up while the intensity of the peaks representing the "original“ complex trans-[RuCl $\left.4(\mathrm{ind})_{2}\right]^{\prime}$ at 3.65 (overlapping the new peak at 3.77), 3.10, 2.34 and $2.18 \mathrm{ppm}$ decreases. The upfield shifted peak at -14.9 disappears. No other signal could be observed. Precipitation occurs after one week at room temperature. This precipitation was only observed at the concentrations used in the NMR experiments. The precipitate is soluble in less polar solvents like chloroform. Although the elemental analysis of the precipitate fits the calculated values for the neutral monosolvento complex $\left[\mathrm{RuCl}_{3}\left(\mathrm{CH}_{3} \mathrm{CN}\right)(\text { ind })_{2}\right]$, the ${ }^{1} \mathrm{H}$ NMR data are not consistent with this proposal. At least eight signals of nearly equal intensity between 9 and $-2 \mathrm{ppm}$ and two broad signals at -12 and $-17 \mathrm{ppm}$ could be detected. Information from COSY spectra are limited due to the paramagnetic $\mathrm{Ru}(\mathrm{III})$ center but coupling between four of the ten signals could be found. 
<smiles></smiles>

a

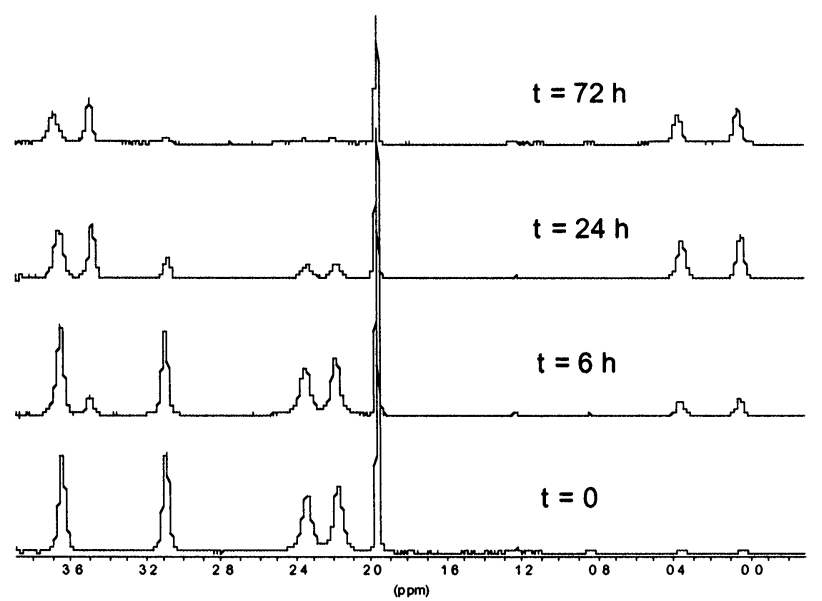

b

Figure 1. a) Tumor-inhibiting Ru(III) complex trans-[RuCl$\left.\left.\left.\right|_{4} i_{2}\right]_{2}\right]^{-}$b) ${ }^{1} \mathrm{H} \mathrm{NMR}$-spectra of $\mathrm{Na}$ trans[RuCl${ }_{4}$ (ind) $)_{2}$ in $\mathrm{CD}_{3} \mathrm{CN} / \mathrm{D}_{2} \mathrm{O}(70 / 30)$ during 3 days at room temperature between a chemical shift of 0 to $3.8 \mathrm{ppm}$.

The changes observed in the UV/vis-spectra also confirm the formation of one main solvolysis product of $\mathrm{Na}$ trans-[RuCl $\left.4_{4} \mathrm{ind}_{2}\right]^{-}$in acetonitrile / water mixtures. The original spectrum with maxima at 239, 292 and $373 \mathrm{~nm}$ changes to give a spectrum with maxima at $279,379,398$, 536 and $635 \mathrm{~nm}$ after 24 hours at $37^{\circ} \mathrm{C}$, as can be seen in figure 2a. Isosbestic points at 217 , 282 and $314 \mathrm{~nm}$ indicate a definite transformation into one main solvolysis product. The changes in the UV/vis-spectra are significantly different from those in pure water (see below).

Thus, solvolysis of $\mathrm{Na}$ trans-[RuCl$\left.{ }_{4}(\text { ind })_{2}\right]$ does not occur in absolute acetonitrile solution within days, whereas it takes place in acetonitrile / water mixtures. One explanation for these findings could be an initial, rate-determining reaction of trans-[RuCl$\left.{ }_{4}(\mathrm{ind})_{2}\right]^{-}$with water, presumably leading to the monoaquacomplex $\left[\mathrm{RuCl}_{3}\left(\mathrm{H}_{2} \mathrm{O}\right)(\mathrm{ind})_{2}\right]$. The monoaquacomplex could then react with acetonitrile, forming an acetonitrile complex $\left[\mathrm{RuCl}_{3}\left(\mathrm{CH}_{3} \mathrm{CN}\right)(\mathrm{ind})_{2}\right]$, as could be demonstrated in similar cases [21].
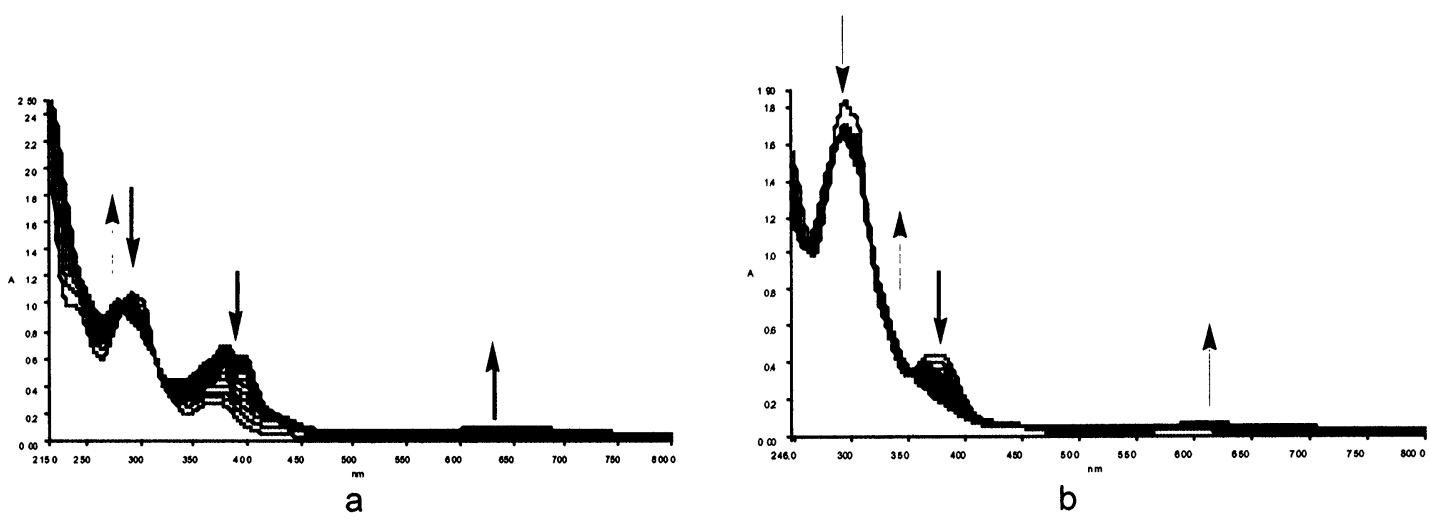

Figure 2. a) UV/vis-spectra $(215-800 \mathrm{~nm})$ of $\mathrm{Na}$ trans-[RuCl$\left.{ }_{4}(\mathrm{ind})_{2}\right]$ in acetonitrile / water $(70 / 30)$ during 48 hours at room temperature; b) UV/vis-spectra $(250-750 \mathrm{~nm})$ of $\mathrm{Na}$ trans-[RuCl$\left.{ }_{4}(\mathrm{ind})_{2}\right]$ in dmso / water $(1 / 1)$ during 12 hours at $37^{\circ} \mathrm{C}$.

As in the case of acetonitrile, no change in the ${ }^{1} \mathrm{H} N M R$ of $\mathrm{Na}$ trans- $\left[\mathrm{RuCl}_{4}(\mathrm{ind})_{2}\right]$ can be observed in absolute dmso-d6 solution within a week. The signals at $-11.0(2 \mathrm{H}$ at C-3), -6.1 (2 $\mathrm{H}$ at N-2), 2.49 (2 H at C-4 or C-7), 3.22 (4 H at C-7 or C-4 and C-5 or C-6) and $4.40 \mathrm{ppm}$ ( $2 \mathrm{H}$ 
at C-6 or C-5) remain unchanged in intensity and chemical shift. The UV/vis-spectra in absolute dmso don't give any evidence for a transformation of the ruthenium complex either. In contrast, the spectra of $\mathrm{Na}$ trans-[RuCl$\left.{ }_{4}(\mathrm{ind})_{2}\right]$ change significantly in dmso / water mixtures. The UV/vis spectrum after 12 hours at $37^{\circ} \mathrm{C}$ is totally different from the spectrum in acetonitrile / water and also different from the spectrum in water (see below). After one hour a band occurs at $610 \mathrm{~nm}$ (in water at $580 \mathrm{~nm}$ ), whereas the band at $377 \mathrm{~nm}$ disappears, as can be seen in figure 2b. Isosbestic points can be found at 261, 283, 312 and $354 \mathrm{~nm}$. No precipitation occurs.

The ${ }^{1} \mathrm{H}$ NMR experiment in dmso-d6/ $\mathrm{D}_{2} \mathrm{O}$ does not lead to further information. No changes in chemical shifts, only a decrease in intensity of the signals due to precipitation of a dark solid can be observed.

The reaction of $\mathrm{Na}$ trans-[RuCl$\left.{ }_{4}(\mathrm{ind})_{2}\right]$ in ethanol can be monitored by UV/vis- and NMRspectroscopy. Figure $3 a$ shows the changes in the ${ }^{1} \mathrm{H}$ NMR spectra of a solution of $\mathrm{Na}$ trans$\left[\mathrm{RuCl}_{4}(\text { ind })_{2}\right.$ ] in ethanol-d4 in the chemical shift region of 2.0 to $4.2 \mathrm{ppm}$. The spectrum at the bottom represents the ${ }^{1} \mathrm{H}$ NMR of $\mathrm{Na}$ trans-[RuCl$\left.{ }_{4}(\text { ind })_{2}\right]$ just after dissolving in deuterated ethanol. The peaks of the original complex anion appear at a chemical shift of 2.24, 2.49, 3.19 and $3.54 \mathrm{ppm}$. After two hours at $37^{\circ} \mathrm{C}$ a peak at $3.13 \mathrm{ppm}$ and two signals at 3.88 and $3.98 \mathrm{ppm}$ arise (they can already be seen in the first spectrum), whereas the intensity of the original peaks decreases. The increase in intensity of the new downfield-shifted signals reaches a plateau after about 12 hours. The signal intensity ratio, original complex I solvolysis product, stays at about $1 / 3$ even after one week. The signal pattern can be attributed to one solvolysis product, as the increase in intensity is simultaneous and coupling of the protons of this solvolysis product can be determined with a $\mathrm{H}, \mathrm{H}-\mathrm{COSY}$ experiment (data not shown). The peaks at 3.13 and $3.98 \mathrm{ppm}$ represent one proton each, the peak at 3.88 $\mathrm{ppm}$ represents two protons of each indazole ligand. Changes in ${ }^{1} \mathrm{H}$ NMR spectra also occur simultaneously in the down field region. The broad signal of the proton at position 3 of the indazole ligand of the original complex anion trans-[ $\left[\mathrm{RuCl}_{4}(\mathrm{ind})_{2}\right]^{-}$at $-14.3 \mathrm{ppm}$ disappears, whereas a new signal rises at $-11.3 \mathrm{ppm}$ (see figure $3 \mathrm{~b}$ ). In the aromatic region multiplets at $7.26,7.51,7.74,7.84 \mathrm{ppm}$ and a singlet at 8.86 can be detected after six hours (data not shown), showing the typical signal pattern for indazole. The signals are of very low intensity (only about $2 \%$ of the main solvolysis product even after a week) and can be attributed to indazole ligands coordinated to diamagnetic ruthenium centers as they are significantly downfield shifted compared to those of free indazole in ethanol-d4 $(7.10,7.34,7.54,7.73$, $8.00 \mathrm{ppm})$.
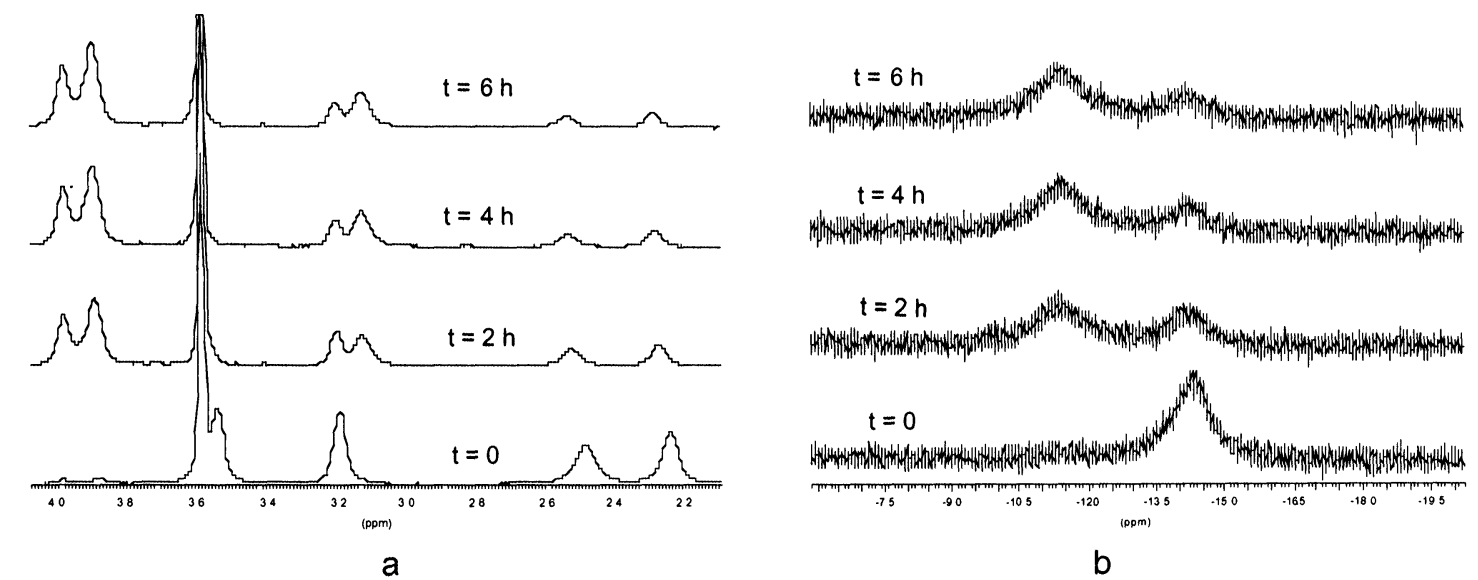

Figure 3. ${ }^{1} \mathrm{H}$ NMR-spectra of $\mathrm{Na}$ trans-[RuCl$\left.{ }_{4}(\text { ind })_{2}\right]$ in ethanol-d6 after $0,2,4$ and 6 hours at $37^{\circ} \mathrm{C}$ between a chemical shift of a) 2.1 and $4.0 \mathrm{ppm}$ (left) and b) -7 and $-20 \mathrm{ppm}$ (right).

The transformation into one main solvolysis product is also obvious in the UV/vis spectra taken at a temperature of $37^{\circ} \mathrm{C}$ during the first six hours (see figure $5 \mathrm{a}$ ). The transformation of the original complex is characterized by isosbestic points at $261,304,339,355$ and $404 \mathrm{~nm}$. No band above $415 \mathrm{~nm}$ can be detected. No further changes, especially no precipitation can be observed within two days of observation period. 
In an ethanol / water mixture (1/1) the changes in the UV/vis-spectra are different. In contrast to the spectra in pure ethanol, a band rises at $578 \mathrm{~nm}$ (see figure $5 \mathrm{~b}$ ). The transformation of the complex is characterized by isosbestic points at $276,310,361$ and $445 \mathrm{~nm}$. Whereas hydrolysis of $\mathrm{Na}$ trans-[RuCl$\left.{ }_{4}(\mathrm{ind})_{2}\right]$ in pure water leads to precipitation (see below), this can not be observed in ethanol / water mixtures.

Four signals at a chemical shift of $-17.9,1.27,2.09,2.41$ and $2.80 \mathrm{ppm}$ can be detected in the ${ }^{1} \mathrm{H}$ NMR spectrum for the complex trans-[RuCl$\left.{ }_{4}(\text { ind })_{2}\right]$, just after dissolving the sodium salt in ethanol / water (1/1). The signals are slightly shifted compared to pure $D_{2} O$ (see below). New signals arise at $1.68,1.87$ and $3.18 \mathrm{ppm}$ but their intensity never exceeds one third of the signals of the "fresh" solution. After three hours a precipitation starts that is finished after eight hours.

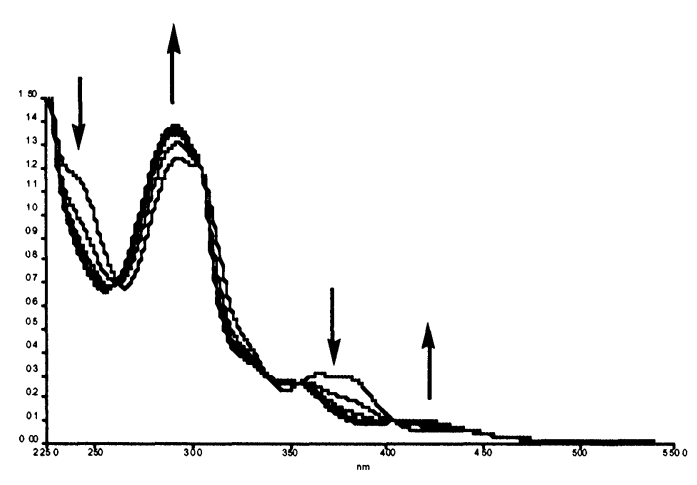

a

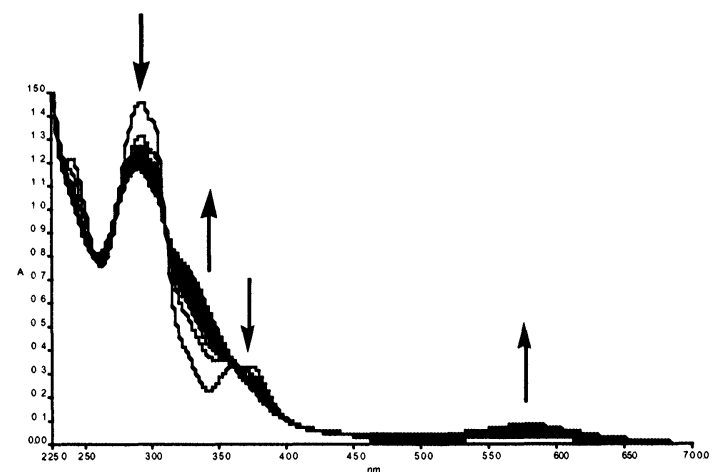

b

Figure 4. UV/vis-spectra of $\mathrm{Na}$ trans-[RuCl$\left.{ }_{4}(\mathrm{ind})_{2}\right]$ in a) ethanol during 6 hours at $37^{\circ} \mathrm{C}(225-550 \mathrm{~nm})$ and b) ethanol / water (1/1) during 12 hours at $37^{\circ} \mathrm{C}(225-700 \mathrm{~nm})$.

HInd trans-[RuCl$\left.l_{4}(\text { ind })_{2}\right]$ reacts quite similar to $\mathrm{Na}$ trans-[RuCl$\left.{ }_{4}(\text { ind })_{2}\right]$. We found no evidence for the interference of the counterion or the formation of the neutral trisindazole complex mer$\left[\mathrm{RuCl}_{3}(\mathrm{ind})_{3}\right]$ under the conditions mentioned. mer- $\left[\mathrm{RuCl}_{3}(\text { ind })_{3}\right]$ can only be obtained on refluxing a suspension of $\mathrm{HInd}$ trans-[RuCl$\left.{ }_{4}(\mathrm{ind})_{2}\right]$ in solvents like tetrahydrofuran or ethyl acetate (to be published).

\subsection{Hydrolysis of $\mathrm{Na}$ trans-[RuCl${ }_{4}$ (ind $\left.)_{2}\right]$}

The hydrolytic reactions of the imidazole complex $\mathrm{HIm}$ trans-[RuCl$\left.{ }_{4}(\mathrm{im})_{2}\right]$ have already been investigated by means of ${ }^{1} \mathrm{H}$ NMR spectroscopy, although the information derived from NMR techniques is limited due to the paramagnetic Ru(III) center. In unbuffered solutions of $\mathrm{HIm}$ trans-[RuCl$\left.{ }_{4}(\mathrm{im})_{2}\right]$ new signals that have been assigned to a monoaqua complex and the two possible diaqua complexes arised. Interpretation of the more complicated spectra obtained in phosphate-buffered solutions was not possible [16].

In contrast to the imidazole complex, no changes in chemical shifts can be observed if a solution of the indazole complex $\mathrm{Na}$ trans-[RuCl$\left.{ }_{4}(\text { ind })_{2}\right]$ in $\mathrm{D}_{2} \mathrm{O}$ is investigated with ${ }^{1} \mathrm{H} N M R$ spectroscopy (The solubility of the indazolium salt HInd trans-[RuCl$\left.{ }_{4}(\text { ind })_{2}\right]$ is not good enough for ${ }^{1} H$ NMR studies). However, precipitation occurs soon and the intensity of the unchanged, paramagnetically shifted peaks at $-18.3,1.30,2.18,2.47$ and $3.04 \mathrm{ppm}$ decreases. Thus, at least one hydrolysis product is formed which immediately precipitates and therefore can't be detected in solution with NMR. A ${ }^{1} \mathrm{H}$ NMR of the precipitate dissolved in dmso-d6 shows signals of the same intensity at a chemical shift of $3.64,3.71,4.19$ and $4.49 \mathrm{ppm}$ presumably belonging to one single paramagnetic species. Additional sharp peaks of much lower intensity (under $2 \%$ ) occur in the aromatic region at 7.17, 7.40,7.80 and $8.75 \mathrm{ppm}$. These signals should derive from coordinated indazole protons of diamagnetic species. In the upfield region two very broad signals at -4 and $-10 \mathrm{ppm}$ can be detected.

One possible hydrolysis product would be the monoaqua complex $\left[\mathrm{RuCl}_{3}\left(\mathrm{H}_{2} \mathrm{O}\right)(\mathrm{ind})_{2}\right]$ or the corresponding hydroxo complex, respectively. The neutral monoaqua complex should be less soluble in water. If it is withdrawn from solution by precipitation, no further hydrolysis reaction could take place and be detected in solution. Nevertheless, the formation of soluble hydrolysis products without NMR-detectable protons, like those of the indazole ligands, can 
not be ruled out (see UV/vis experiments). An elemental analysis of the precipitate of $\mathrm{Na}$ trans-[RuCl$\left.l_{4}(\text { ind })_{2}\right]$ in water is within a tolerable margin for $\mathrm{C}, \mathrm{H}$ and $\mathrm{N}$ but the $\mathrm{Cl}$ content differs by $1.1 \%$ from the value calculated for the monoaquacomplex. The crystal structure of the monoaqua complex of the $\mathrm{N}-1$ methylated indazole complex $\left[\mathrm{RuCl}_{3}\left(\mathrm{H}_{2} \mathrm{O}\right)(1-\mathrm{Me} \text {-ind })_{2}\right]$ could already be solved [17]. The crystals could be obtained by evaporating a solution of $\mathrm{H}$ (1-Me-ind) trans-[RuCl $\left.3\left(\mathrm{H}_{2} \mathrm{O}\right)(1-\mathrm{Me} \text {-ind })_{2}\right]$ in acetone / water (1/1).

In contrast to the NMR experiments, changes of a solution of $\mathrm{Na}$ trans- $\left[\mathrm{RuCl}_{4}(\mathrm{ind})_{2}\right]$ in water can be seen in the UV/vis-spectra. Figure 5a shows the changes in the UV/vis spectra during the first eight hours at $37^{\circ} \mathrm{C}$. Together with the formation of a band at $578 \mathrm{~nm}$ a diffused background absorption caused by precipitation can be observed, resulting in an increased baseline. Nevertheless, one has to be aware of the more than 100 times smaller concentration of $\mathrm{Na}$ trans-[RuCl$\left.{ }_{4}(\mathrm{ind})_{2}\right]$ in the solution of the UV/vis compared to the NMR experiment. Therefore, different hydrolysis pathways can not be excluded.

Hydrolysis, of course, proceeds slower at room temperature or at $4^{\circ} \mathrm{C}$, where no changes in UV/vis spectra can be observed even after days. This is important to notice with regard to a clinical application and storage of solutions of $\mathrm{Na}$ trans-[RuCl$\left.{ }_{4}(\mathrm{ind})_{2}\right]$.

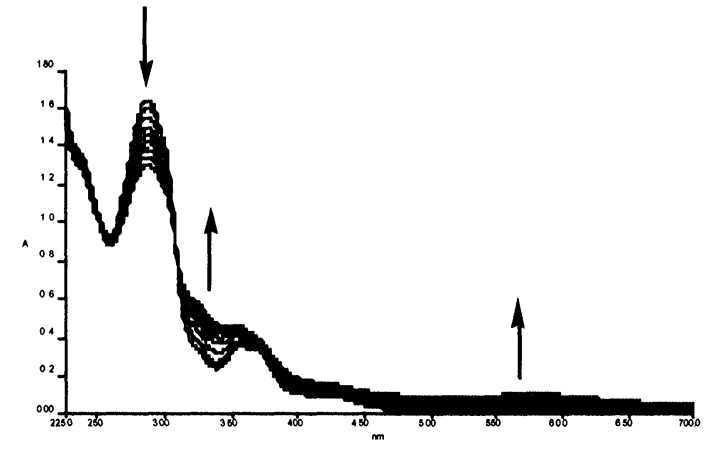

a

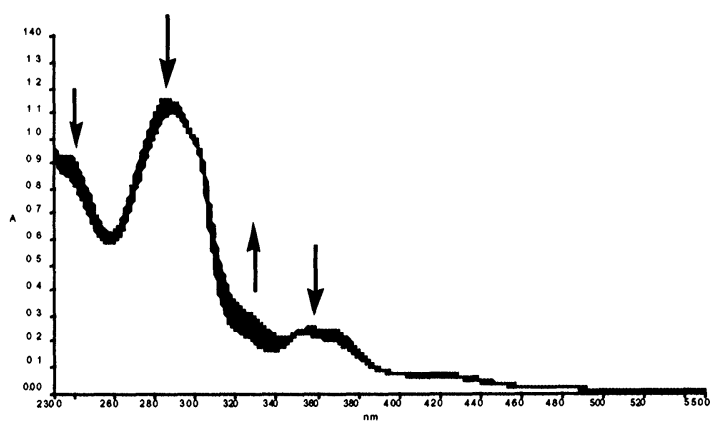

b

Figure 5. a) UV/vis spectra $(225-670 \mathrm{~nm})$ of $\mathrm{Na}$ trans-[RuCl $\left.4(\mathrm{ind})_{2}\right]$ in aqueous solution at $37^{\circ} \mathrm{C}$ during the first 8 hours; b) UV/vis spectra $(225-550 \mathrm{~nm})$ of $\mathrm{Na}$ trans-[RuCl$\left.{ }_{4}(\text { ind })_{2}\right]$ at $37^{\circ} \mathrm{C}$ over $10 \mathrm{~min}$ in a buffer consisting of $0.004 \mathrm{M} \mathrm{NaH}_{2} \mathrm{PO}_{4}, 0.025 \mathrm{M} \mathrm{NaHCO}_{3}$ and $0.1 \mathrm{M} \mathrm{NaCl}$.

Reaction of $\mathrm{Na}$ trans-[RuCl$\left.\left(\mathrm{R}_{4} \text { (ind }\right)_{2}\right]$ in a solution buffered to $\mathrm{pH} 7.4$ with phosphate buffer is faster than in pure water $\left(D_{2} O\right)$. ${ }^{1} H$ NMR spectra give only little information about the hydrolytic process as precipitation occurs even faster and only a decrease in intensity but no change in the chemical shifts of the protons assigned to the complex trans-[RuCl$\left(\mathrm{ind}_{2}\right]^{-}$can be detected. The dark precipitate is poorly soluble in dmso. The H NMR in dmso-d6 reveals a number of signals similar to those of the precipitate obtained in pure water and additional four small signals between 11.5 and $13 \mathrm{ppm}$. The signals between 7.1 and $8.8 \mathrm{ppm}$ are more intense as in the case of the pure water solution (about 25\%). The UV/vis spectra are quite similar to those for pure water, revealing the formation of a band at $578 \mathrm{~nm}$ and precipitation. Hydrolysis of the complex trans-[RuCl$\left.{ }_{4}(\text { ind })_{2}\right]^{-}$is much slower at lower $\mathrm{pH}$ levels, whereas it is significantly faster at higher $\mathrm{pH}$ levels. If the $\mathrm{pH}$ of a solution of trans-[RuCl$\left.{ }_{4}(\mathrm{ind})_{2}\right]^{-}$at $37^{\circ} \mathrm{C}$ is adjusted to 3.5 with orthophosphoric acid, the transformation of the complex is indicated by intensity changes of the bands at 287, 357 and $417 \mathrm{~nm}$ and isosbestic points at 272, 308 and $344 \mathrm{~nm}$ in the UV/vis spectra during the first five hours after dissolving the complex. After this initial transformation further changes in the UV/vis spectra can be detected, characterized by isosbestic points at 357,464 and $647 \mathrm{~nm}$ and the formation of a new band at $578 \mathrm{~nm}$. The band at $578 \mathrm{~nm}$ reaches its maximum after $60 \mathrm{~h}$ at $37^{\circ} \mathrm{C}$, followed by a decrease in absorbance in the whole wave length region because of precipitation. This band at $578 \mathrm{~nm}$ is a good indicator to demonstrate the $\mathrm{pH}$-dependence of the hydrolysis. Figure 6 a shows a plot of the time after first appearence of the band at $578 \mathrm{~nm}$ in the visible spectra against the $\mathrm{pH}$ of buffered solutions of $\mathrm{Na}$ trans-[RuCl$\left.{ }_{4}(\text { ind })_{2}\right]$.

$\mathrm{Na}$ trans-[RuCl${ }_{4}$ (ind $\left.)_{2}\right]$ and $\mathrm{HInd}$ trans- $\left[\mathrm{RuCl}_{4}(\text { ind })_{2}\right]$ show a total different behaviour if $\mathrm{NaHCO}_{3}$ is present in aqueous solution or if a physiological buffer, consisting of $0.004 \mathrm{M} \mathrm{NaH}_{2} \mathrm{PO}_{4}, 0.025$ $\mathrm{M} \mathrm{NaHCO}_{3}$ and $0.1 \mathrm{M} \mathrm{NaCl}$, is used, respectively. A solution of $\mathrm{Na}$ trans-[ $\left[\mathrm{RuCl}_{4}(\mathrm{ind})_{2}\right]$ in this 
$\mathrm{HCO}_{3}{ }^{-}$containing buffer $(\mathrm{pH} 7.4)$ changes color to green and further on to green-blue within minutes and precipitation occurs after 15 minutes. Figure $6 \mathrm{~b}$ shows repetitive scan spectra during the first ten minutes, revealing the formation of one new species, characterized by isosbestic points at 298 and $350 \mathrm{~nm}$. After standing for one day the solution is totally colorless. The ${ }^{1} \mathrm{H}$ NMR of the precipitate dissolved in dmso-d6 reveals sharp signals at 8.06 [s, $\mathrm{H}$ at C-3], 7.74[m, H at C-4], 7.52 [m, H at C-7], 7.32 [m, H at C-5], 7.08 [m, H at C-6] and $13.06 \mathrm{ppm}$ that fit perfectly the chemical shifts of the indazolium ion in dmso-d6 solution. These signals are overlapped by a very broad signal centered at $7.2 \mathrm{ppm}$ (see figure 6b). No other signals could be detected. Thus, the indazole ligands seem to be released, at least in part. Whether the precipitate consists of a monomeric, dimeric or polymeric species or a mixture of species can not be ruled out based on these investigations.

Important to notice is the fact that $\mathrm{HCO}_{3}{ }^{-}$has no comparable influence on the hydrolysis of $\mathrm{HIm}$ trans-[RuCl$\left.{ }_{4}(\mathrm{im})_{2}\right]$. Whereas hydrolysis of the imidazole complex is faster in water or phosphate buffer, the situation changes dramatically in buffer systems containing hydrogen carbonate. In these buffer systems also binding towards serum proteins was found to be faster. If a citrate / phosphate buffer is used a similar behaviour can be observed, probably due to reaction of the ruthenium center with the carboxylato groups.

a

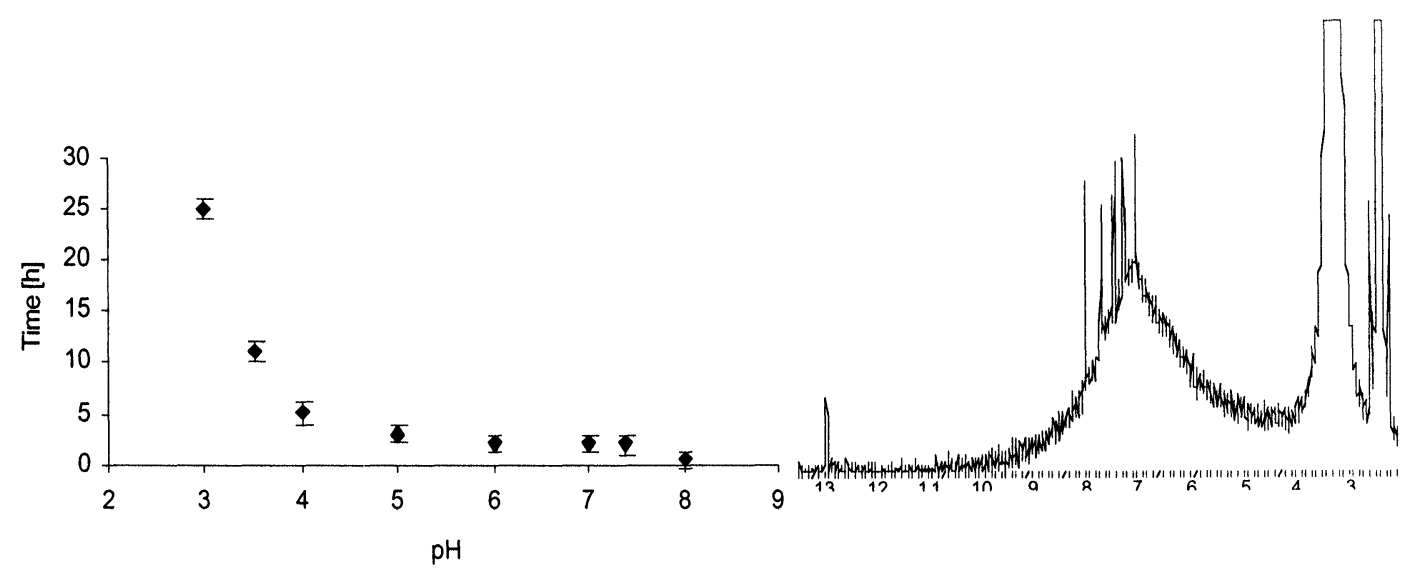

Figure 6. a) Time of first appearance of the band at $578 \mathrm{~nm}$ in visible spectra of $\mathrm{Na}$ trans-[RuCl $\left.\mathrm{R}_{4}(\mathrm{ind})_{2}\right]$ at different $\mathrm{pH}$ values of buffered solutions at $37^{\circ} \mathrm{C}$; b) ${ }^{1} \mathrm{H}$ NMR in dmso-d6 of the precipitate obtained from a solution of $\mathrm{Na}$ trans-[RuCl 4 (ind) $\left.)_{2}\right]$ in a buffer consisting of $0.004 \mathrm{M} \mathrm{NaH}_{2} \mathrm{PO}_{4}, 0.025 \mathrm{M} \mathrm{NaHCO}_{3}$ and 0.1 $\mathrm{M} \mathrm{NaCl}$.

\subsection{Conclusions}

Whereas solvolysis of the complex trans-[RuCl$\left.{ }_{4}(\mathrm{ind})_{2}\right]^{-}$in organic solvents or aqueous mixtures of solvents like ethanol, acetonitrile and dmso seems to lead for the most part to one main product, hydrolysis in water or buffered aqueous solution is more intricate. Solvolysis in ethanol and acetonitrile / water presumably leads to neutral, monosubstituted ruthenium solvento complexes.

The solvolytic decomposition of the complex trans-[RuCl$\left.l_{4}(\text { ind })_{2}\right]^{-}$is characterized by substitution of one or more of the chloro ligands. An initial formation of the neutral monoaquacomplex $\left.\left[\mathrm{RuCl}_{3}\left(\mathrm{H}_{2} \mathrm{O}\right) \text { (ind) }\right)_{2}\right]$ seems to be necessary for further transformation in all solvent systems as no reaction occurs in absolute dmso and acetonitrile within days. The formation of an aquacomplex is also likely because $\mathrm{pH}$ decreases in an unbuffered solution of $\mathrm{Na}$ trans-[RuCl$\left.{ }_{4}(\mathrm{ind})_{2}\right]$ in water (data not shown). This lowering of $\mathrm{pH}$ should be caused by a deprotonation of the formed aquacomplex(es), leading to the corresponding hydroxocomplex(es). The formed hydroxo complexes could then further react to di- or polynuclear hydroxo- or oxo-bridged species, respectively. These reactions should be accelerated at higher $\mathrm{pH}$ levels. As we found a strong $\mathrm{pH}$ dependence of the hydrolysis, the formation of $\mu$-oxo complexes might be one of the possible reaction pathways. Additionally, a release of the indazole ligands can not be excluded although the Ru(III)-nitrogen bonds in 
these kind of ruthenium complexes with $\mathrm{N}$-heterocyclic ligands are assumed to be rather inert.

A totally different hydrolysis pathway is followed in the case of the buffer containing $\mathrm{NaHCO}_{3}$. The hydrolysis is much faster and release of indazole could be demonstrated.

This striking influence of $\mathrm{HCO}_{3}{ }^{-}$on the hydrolytic decomposition of trans-[RuCl$\left.{ }_{4}(\mathrm{ind})_{2}\right]^{-}$is important to notice, especially in comparison to the imidazole complex trans-[RuCl$\left.{ }_{4}(\mathrm{im})_{2}\right]$.

Whereas the imidazole complex hydrolyzes faster than the indazole complex in water or phosphate buffer, the situation changes dramatically in physiological buffer containing hydrogen carbonate. A total change in the coordination sphere of the ruthenium complex seems to take place. The formed species react very fast with serum proteins under these conditions [22] (No precipitation occurs if serum proteins are present). Whereas the indazole complex is more stable in water than the imidazole complex, and enough stable with regard to a clinical application, reactions in the blood can proceed much faster compared to the imidazole complex. This might be one of the reasons for the significantly lower toxicity of the indazole complex.

\section{Acknowledgements}

The assistance of Mrs. Rosa Strobl in preparing the manuscript is gratefully acknowledged. The research is sponsored by the Fonds zur Förderung der wissenschaftlichen Forschung (FWF).

\section{References}

[1] Clarke, M.J. in Metal Complexes in Cancer Chemotherapy, Ed. Keppler, B.K.; VCH Weinheim, (1993), 129.

[2] Alessio, E.; Balducci, A.; Lutman, A.; Mestroni, G.; Calligaris, M.; Attia, W.M.; Inorg. Chim. Acta (1993), 203, 205.

[3] Vilaplana, R.; Romero, M.A.; Quiros, M.; Salas, J.M.; Gonzalez-Vilchez, F.; Metal Based Drugs (1995), 2, 211

[4] Mestroni, G.; Alessio, E.; Sava, S.; Pacor, S.; Coluccia M., Boccarelli, A.; Metal Based Drugs (1993), 1, 41.

[5] Keppler, B. K.; Lipponer, K. G.; Stenzel, B.; Kratz, F.; Metal Complexes in Cancer Chemotherapy, Ed. Keppler, B.K.; VCH Weinheim, (1993), 187.

[6] Seelig, M.; Berger, M.R. ; Keppler, B.K.; Schmähl, D.; Metal lons in Biology and Medicine; Eds. 'Collery, Ph.; Poirier, L.A.; Manfait, M.; Etienne, J.C.; John Libbey Eurotext: Paris, (1990), 476.

[7] Galeano, A.; Berger, M.R.; Keppler, B.K.; Arzneimittelforschung/Drug Research (1992), $42(1), 821$.

[8] Depenbrock, H.; Schmelcher, S.; Peter, R.; Keppler, B.K.; Weirich, G.; Block, T.; Rastetter, J.; Hanauske, A. R.; Europ. J. Cancer (1997), 33, 2404.

[9] Howe-Grant, M.; Lippard, S.L.; Metal lons Biol. Syst. (1980), 11, 63.

[10] Hohmann, H.; Hellquist, B.; van Eldik, R.; Inorg. Chem. (1992), 31, 1090.

[11] Hohmann, H.; van Eldik, R.; Inorg. Chim. Acta (1990), 174, 87.

[12] Suvachittanont, S.; van Eldik, R.; Inorg. Chem. (1994), 33, 895.

[13] Holler, E.; Schaller, W.; Keppler, B.K.; Arzneim.-Forsch. / Drug Res. (1991), 41, 1065.

[14] Chatlas, J.; van Eldik, R.; Keppler, B.K.; Inorg. Chim. Acta (1995), 233, 59.

[15] Anderson, C.; Beauchamp, A.L.; Can. J. Chem. (1995), 73, 471.

[16] Ni Dhubhghaill, O.M.; Hagen, W.R.; Keppler, B.K.; Lipponer, K.G.; Sadler, P.J.; J. Chem. Soc. Dalton Trans. (1994), 3305.

[17] Lipponer, K.G.; Vogel, E.; Keppler, B.K.; Metal-Based Drugs (1996), 3, 243.

[18] Peti, W.; Pieper, T.; Sommer, M.; Keppler, B.K.; Giester, G.; Eur. J. Inorg.Chem. (1999), 1551.

[19] Bertini, I.; Luchinat, C.; NMR of paramagnetic molecules in biological systems, Benjamin-Cummings: Menlo Park, CA, (1986).

[20] Satterlee, J.D.; Concepts Magn. Reson. (1990), 2, 69 and (1990), 2, 119.

[21] Velders, A.H.; Pazderski, L.; Ugozzoli, F.; Biagini-Cingi, M.; Manotti-Lanfredi, A.M.; Haasnoot, J.G.; Reedijk, J.; Inorganica Chimica Acta (1998), 273, 259.

[22] Kratz, F.; Hartmann, M.; Keppler, B.K.; Messori, L.; J. Biol. Chem. (1994), 269, 2581.

Received: May 22, 2000 - Accepted: August 22, 2000 Received in revised camera-ready format: August 23, 2000 